\title{
Physical and mechanical properties of composites based on hemp shives and lime
}

\author{
Przemysław Brzyski ${ }^{1, *}$, Grzegorz Łagód ${ }^{2}$ \\ ${ }^{1}$ Lublin University of Technology, Faculty of Civil Engineering and Architecture, Department of \\ Construction, Nadbystrzycka Str. 40, 20-618 Lublin, Poland \\ ${ }^{2}$ Lublin University of Technology, Faculty of Environmental Engineering, Department of Water \\ Supply and Sewage Removal, Nadbystrzycka Str. 40B, 20-618 Lublin, Poland
}

\begin{abstract}
One of the objectives of sustainable development in construction is the use of low-processed materials. They have a positive impact on the ecological balance of the building throughout the entire life cycle. Examples of such materials are materials of plant origin - straw, shives, cellulose fibers. They are used as thermal insulation or wall material. In recent years, hemp shives are increasingly used as a component of a lime-based composite, which performs the function of wall filling in timber frame constructions. The shives, due to the high porosity, determine the high thermal insulation properties of the composite. The physico-mechanical properties of the composite can be modified depending on various factors, including the ratio of hemp shives to the binder. The lime binder, in turn, can be modified by hydraulic and pozzolan additives. The paper presents mechanical properties (compressive and flexural strength) as well as physical properties (density, porosity, thermal conductivity coefficient, absorbability) of composites with various proportions of hemp shives of the Bialobrzeskie variety to the lime binder modified with Portland cement and metakaolinite.
\end{abstract}

\section{Introduction}

The share of construction industry in energy consumption in the European Union is significant and amounts to about 40\% [1]. Construction industry is also the source of a significant amount of waste, difficult to dispose of. An alternative to high-energy building materials used nowadays is the possibility of using plant-based materials. Materials obtained from plants are used in the building industry mainly as thermal insulation. Investigations on the use of hemp, flax and wood fibers as insulation in loose or mat form [2] were carried out. In addition to fibers, the possibility of using wooden parts of plants, such as hemp [3, 4], flax shives [3] or rape straw [5], in the building industry is also being investigated. These materials are characterized by high porosity, low thermal conductivity and high thermal capacity. They are used, for example, as fillers in composites based on lime or clay binder. These composites are used as filling walls made of a wooden frame technology. The most commonly used binder in these composites is hydrated lime. It is

*Corresponding author: p.brzyski@pollub.pl 
an air binder characterized by high vapour permeability and resistance to biological corrosion due to high $\mathrm{pH}$. However, it has low strength parameters, and the binding and hardening process is slow and uneven. For this reason, to provide early strength and partially hydraulic properties of the lime binder the additives are used.

This paper describes the results of research on the possibility of using renewable agricultural raw materials such as hemp shives with lime binder in the construction industry. Analysis of mechanical properties (compressive and flexural strength) as well as physical properties (density, porosity, thermal conductivity coefficient, absorbability) of composites with various proportions of hemp shives to the lime binder modified with Portland cement and metakaolinite are presented.

\section{Materials and methods}

\subsection{Materials and recipes}

Research was conducted on composite based on modified lime binder and aggregate substitute as hemp shives of the Białobrzeskie variety. Four recipes have been investigated that differed in proportion of applied compounds. Hemp filler is characterized by a high porosity (about $80 \%$ ), low apparent density (about $110 \mathrm{~kg} / \mathrm{m}^{3}$ ) and high weight absorptivity (about $400 \%$ dry weight after $48 \mathrm{~h}$ of soaking). Hemp shives used in investigation are shown in Figure 1.

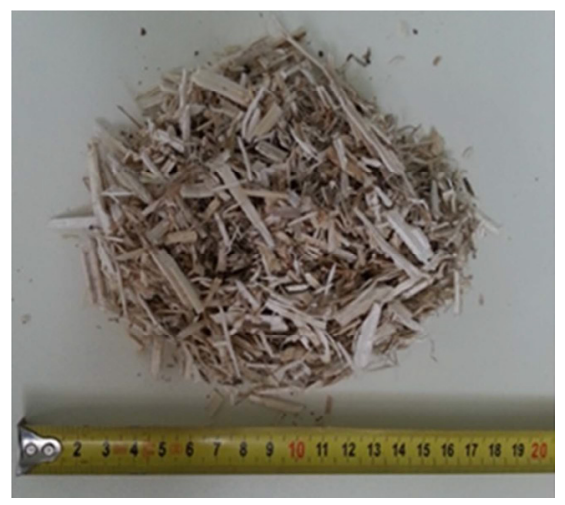

Fig. 1. Hemp shives used in studies.

CL-90s hydrated lime was used as the main binder. This material, due to its high alkalinity and vapour permeability, is the most appropriate binder which contains organic fillers in construction materials. The addition of Portland cement, classified as CEM II/B-V $32.5 \mathrm{R}$, was designed to increase the composite early strength, which is important because of its final use in the walls of a monolith. Metakaolinite was used as another additive. It is a highly reactive pozzolan, containing $\mathrm{SiO}_{2}$ and $\mathrm{Al}_{2} \mathrm{O}_{3}$ in an amorphous form. In conjunction with $\mathrm{Ca}(\mathrm{OH})_{2}$ in the lime, hydrated calcium silicates and hydrated calcium aluminiosilicates are created, which increase the strength of the material and partial hydraulic properties of composite. The composite recipes are shown in Table 1 and Table 2. 
Table 1. Compositions of composites.

\begin{tabular}{|c|c|c|}
\hline Composite & Binder : filler weight ratio & Binder : water weight ratio \\
\hline HLC1 & $2: 1$ & 2.8 \\
\hline HLC2 & $1.83: 1$ & 2.65 \\
\hline HLC 3 & $1.67: 1$ & 2.5 \\
\hline HLC4 & $1.5: 1$ & 2.35 \\
\hline HLC means Hemp Lime Composite \\
\hline
\end{tabular}

Table 2. Recipes of composites (the percentage of binder and filler components).

\begin{tabular}{|c|c|c|c|c|}
\hline \multirow{2}{*}{ Composite } & \multicolumn{3}{|c|}{ Binder components [\%] } & Filler components [\%] \\
\cline { 2 - 5 } & Hydrated lime & Cement CEM II/B-V 32.5R & Metakaolinite & Hemp shives \\
\hline All recipes & 70 & 15 & 15 & 100 \\
\hline
\end{tabular}

\subsection{Methods}

\subsubsection{Preparation of the samples}

Mixture preparation consisted in mixing binding materials with water and then gradually adding the liquid binder to the pre-mixed filler components. Mixing continued until the hemp shives and other fillers were covered by the paste and a uniform consistency was obtained. All of the samples used in the investigation were maturating in laboratory conditions (air temperature $20^{\circ} \mathrm{C} \pm 2^{\circ} \mathrm{C}$, air relative humidity $55 \% \pm 5 \%$ ) for 28 days after preparation.

\subsubsection{Apparent density, specific density, porosity}

The apparent density and total porosity tests were carried out according to standard EN 12390-7:2001 on five cubic specimens of dimensions $100 \times 100 \times 100 \mathrm{~mm}$ from each recipes. The specimens of known volume were dried, and then weighed on a laboratory scale in order to calculate the apparent density. The density of the composites was determined by means of the pycnometric method in accordance with EN 1936:2010. The porosity was calculated based on determined density.

\subsubsection{Mass absorptivity}

The absorptivity test was carried out according to EN 13755 on five cubic specimens from each mixtures, with the dimensions of $100 \times 100 \times 100 \mathrm{~mm}$. The test consisted in controlling an increase in weight of the samples soaked with water until the state of total saturation occurred. The specimens were soaked in water for about 7 days.

\subsubsection{Thermal conductivity coefficient}

The thermal conductivity test of the mortars was carried out on specimens with the dimensions of $250 \times 250 \times 50 \mathrm{~mm}$. The measurement was conducted using plate apparatus FOX314 in accordance with ISO 8302 method. Before the test, the samples were dried to constant mass in an oven at $60^{\circ} \mathrm{C}$. In the thermal conductivity test, the temperature set on a hot plate was $25^{\circ} \mathrm{C}$ and $0^{\circ} \mathrm{C}$ on a cooling plate, and the average temperature obtained was $12.5^{\circ} \mathrm{C}$. The test result was the average thermal conductivity of the mortar obtained from three specimens. The absolute thermal conductivity accuracy of the plate apparatus FOX 314 was $\pm 2 \%$. 


\subsubsection{Compressive and flexural strength}

The compressive strength was determined after 28 days of maturation on 5 cubic samples with the following dimensions: $150 \times 150 \times 150 \mathrm{~mm}$ for each mixture, using a hydraulic press with a load range of $0-250 \mathrm{kN}$. In this study the press head was controlled by the displacements with a value of $5 \mathrm{~mm} / \mathrm{min}$. The loads and displacements were measured. Flexural strength was determined on 3 specimens with the following dimensions $100 \times 100 \times 500 \mathrm{~mm}$ for each mixture. The research was conducted according to EN 12390-5:2009. The test was run after 28 days of sample maturation. The samples were then loaded with a centrally placed force (3-point-bending). Spacing of the supports was $300 \mathrm{~mm}$. The load increase was set at $50 \mathrm{~N} / \mathrm{s}$.

\section{Results and discussion}

\subsection{Apparent density, specific density and total porosity}

Apparent density of the tested composites ranged between 404.4 and $483.5 \mathrm{~kg} / \mathrm{m}^{3}$ (Table 3 ). It can be seen that the apparent density increases proportionally to the lime binder content. The binder is characterized by a five times higher apparent density than the shives. Increasing the amount of binder in the mix (in the amounts used in own research), however, does not increase the volume of the composite, because the binder fills the voids between the shives placed against each other. In other studies [6], the shives : binder weight ratio was used in the same manner as in the HLC1 recipe (1:2). The value of apparent density was between 508 and $627 \mathrm{~kg} / \mathrm{m}^{3}$. The difference in comparison with own research could be related to the compaction force [7] or the size of shives. The obtained apparent density values can be compared to the apparent density of composites based on other plant components, eg flax shives $\left(405-467 \mathrm{~kg} / \mathrm{m}^{3}[3]\right)$ or rape straw $\left(487 \mathrm{~kg} / \mathrm{m}^{3}[5]\right)$.

Table 3. Density and porosity of tested composites.

\begin{tabular}{|c|c|c|c|}
\hline Composite & Apparent density $\left[\mathbf{k g} / \mathbf{m}^{\mathbf{3}}\right]$ & Specific density $\left[\mathbf{k g} / \mathbf{m}^{\mathbf{3}}\right]$ & Total porosity [\%] \\
\hline HLC1 & 483.5 & $2,270.0$ & 78.7 \\
\hline HLC2 & 457.1 & $2,229.8$ & 79.5 \\
\hline HLC3 & 428.6 & $2,153.8$ & 80.1 \\
\hline HLC4 & 404.4 & $2,106.3$ & 80.8 \\
\hline
\end{tabular}

Total porosity of the tested composites ranged between 78.7 and $80.1 \%$ (Table 3). In each recipe of hemp-lime composite the total porosity is maintained at a high level, due to technological possibilities of the composite preparation (compaction). Different shapes of hemp shives cause them to randomly form an air voids between the individual shives during the compaction of mix. According to Rahim's research [5] composites porosity was comparable - hemp composite with apparent density of $478 \mathrm{~kg} / \mathrm{m}^{3}$ indicated total porosity equal to $76.4 \%$ and rape straw composite with apparent density of $487 \mathrm{~kg} / \mathrm{m}^{3}$ indicated total porosity equal to $75.1 \%$. Other research [8] has presented that composite revealed total porosity of $79 \%$ with the apparent densities of $430-460 \mathrm{~kg} / \mathrm{m}^{3}$.

\subsection{Mass absorptivity}

Mass absorptivity of the tested composites during 7 days of saturation is shown in Figure 2. 


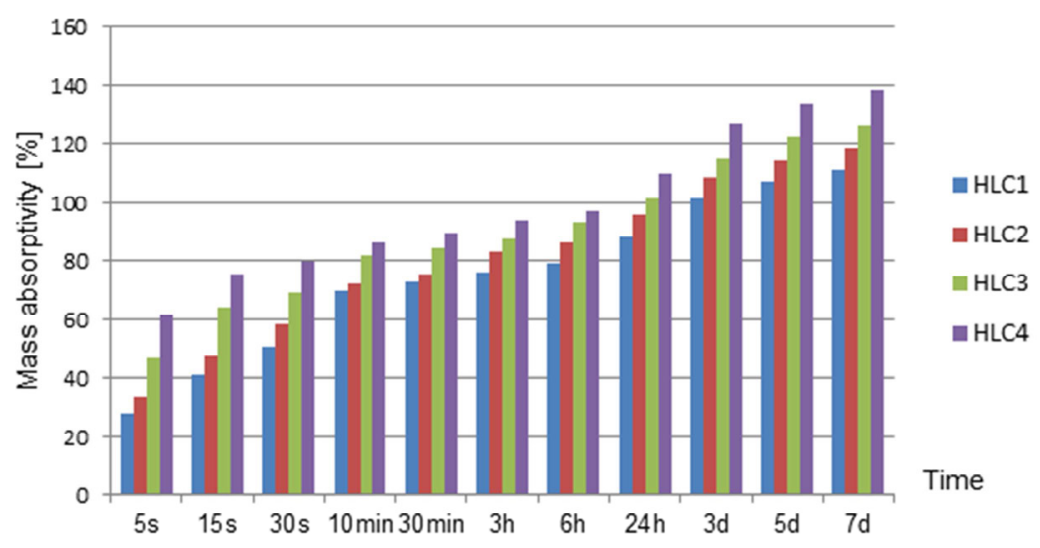

Fig. 2. Mass absorptivity of tested composites over time.

Mass absorptivity of composites ranges from 111.2 to $138.2 \%$. Similar effects were obtained by using other porous organic materials as filler in composite - flax shives (mass absorptivity in the range of $89.3-148 \%$ [3]). As the content of lime binder increases, the composite absorptivity decreases. The greater the amount of binder, the surface of the shives was more sealed, thereby reducing the absorption of water by them. Each of the tested composites is characterized by high water absorption. This is due to the high total porosity of the composites as well as to the significant content of hygroscopic organic fillers as well. Hemp shives are able to absorb water in the amount of three times their own weight, which is also confirmed by research reports in literature [9]. The greatest increase in absorptivity was observed in the first seconds after immersing the composite in water. After the first $5 \mathrm{~s}$, the absorptivity ranged from 27.8 to $61.5 \%$. It is important to protect the hemp-lime external even before short-term contact with water. Similar observations are described in the literature [10], where after the first 5 seconds of immersing in water, the mass absorption of hemp-perlite-lime composites was in the range of $29-62 \%$.

Relationship between mass absorptivity of a composite and its apparent density is presented in Figure 3. It can be assumed that this relation is linear and the coefficient of determination $\left(\mathrm{R}^{2}\right)$ for the tested composites is equal to 0.929 .

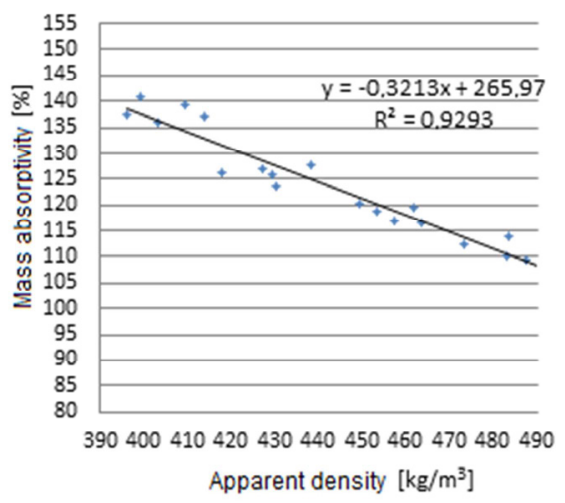

Fig. 3. Relationship between mass absorptivity and apparent density of hemp-lime composites. 


\subsection{Thermal conductivity coefficient}

The results of the thermal conductivity are shown in Figure 4. Error bars mean confidence intervals for the average.

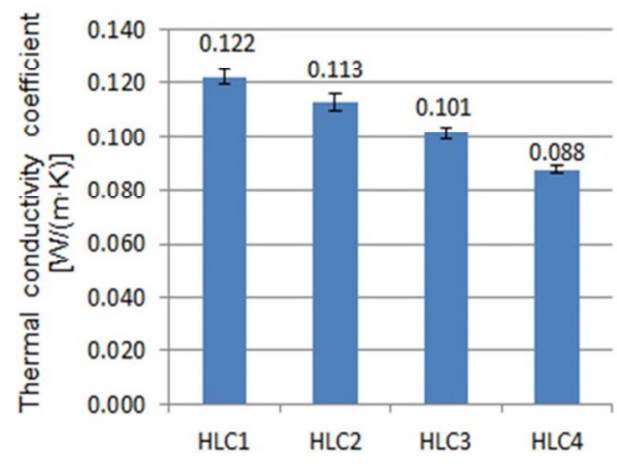

Fig. 4. Thermal conductivity coefficient of composites.

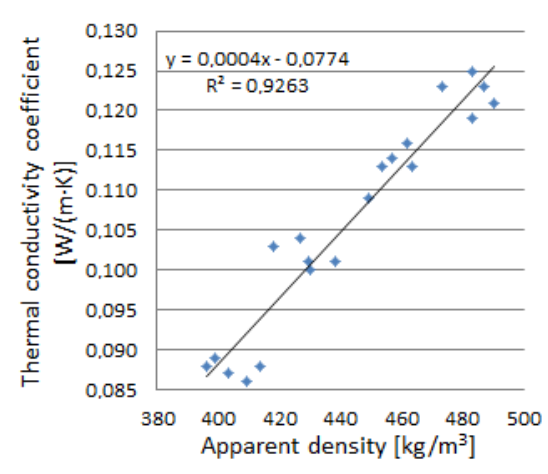

Fig. 5. Relationship between thermal conductivity and apparent density of hemp-lime composites.

Thermal conductivity coefficient of composites ranges from 0.088 to $0.122 \mathrm{~W} /(\mathrm{m} \cdot \mathrm{K})$. As the binder content increases, the thermal conductivity coefficient of the composite increases. This observation is confirmed by the results of research presented in the literature [11]. Increasing the binder content in the composition means reducing the porosity of the composite, thus reducing the amount of closed air in the composite structure. The coefficient of thermal conductivity of the lime binder is about $0.7 \mathrm{~W} /(\mathrm{m} \cdot \mathrm{K})$, i.e. it is about 12 times larger than the $\lambda$ coefficient of hemp shives [12].

The value of the thermal conductivity coefficient $\lambda$ of the lime-hemp composite depends on the density of the material, which in turn is related to the method of laying and compacting the mixture and the proportion of binder to the filler. According to the literature $[6-8,11,13]$ and the results of own research, the value of the conductivity coefficient increases with the increase of the apparent density of hemp-lime composites. Similar observations were obtained for composites based on flax shives, for apparent density $405 \mathrm{~kg} / \mathrm{m}^{3}$, the $\lambda$ coefficient was $0.082 \mathrm{~W} /(\mathrm{m} \cdot \mathrm{K})$, while for density $467 \mathrm{~kg} / \mathrm{m}^{3}$, the thermal conductivity increased to $0.112 \mathrm{~W} /(\mathrm{m} \cdot \mathrm{K})$ [3].Relationship between the thermal conductivity of a composite and its apparent density is presented in Figure 5. It can be assumed that this relation is linear and the coefficient of determination $\left(\mathrm{R}^{2}\right)$ for the tested composites is equal to 0.926 .

\subsection{Compressive and flexural strength}

The results of the investigated mechanical properties of composites are shown in Figure 6. Error bars mean confidence intervals for the average. 
a)

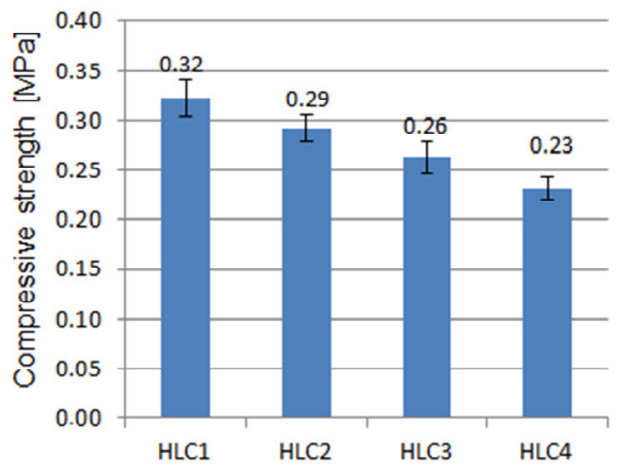

b)

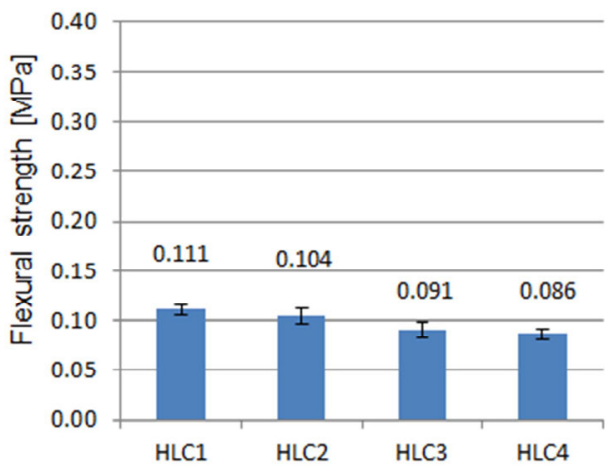

Fig. 6. Compressive strength (a) and flexural strength (b) of tested composites.

The compressive strength of composites ranges from 0.23 to $0.32 \mathrm{MPa}$ and the flexural strength ranges from 0.086 to $0.111 \mathrm{MPa}$. The obtained strength values can be compared to the strength parameters of composites based on other plant components, eg flax shives (compressive strength in the range of $0.51-0.85 \mathrm{MPa}$ and flexural strength in the range of 0.09-0.24 MPa [3]). According to the literature, the strength parameters depend on the type of binder, its ratio to the filler, the fraction of shives, as well as the method of mixture compaction $[3,4,6]$. In this study, as the amount of binder increases, the compressive and flexural strength increases. However, the results are not varied. The amount of binder affects the strength, however, it is also important to influence hemp shives, especially those with longer fractions and fibers which are micro reinforcement. The shives decided about the obtained form of deformation during and after the load test.

At the moment of obtaining a deflection arrow of $20 \mathrm{~mm}$, the samples did not completely break, but only experienced deflections and scratches (Fig. 7a). It is an advantage of building materials based on fibrous and wooden components, in contrast to materials based on mineral aggregate and cement, where the destruction under load is carried out in an explosive way. During the compression test, the composite exhibits elastic properties in the initial phase. When bonding forces are broken, the composite undergoes deformation and compression. The shives deform to gradually adjust to the cracks and empty voids between shives (Fig. 7b.).
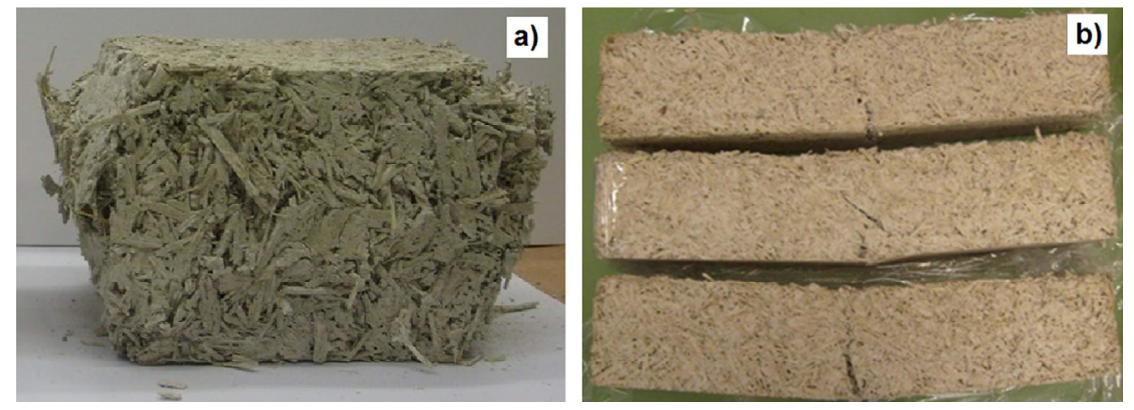

Fig. 7. The form of destruction of a composite sample after a compression (a) and bending (b) test. 


\section{Conclusions}

The paper presents the results of research and related discussion on the properties of composites consisting of binder (based on lime) and fillers: the hemp shives of Białobrzeskie hemp variety. It was shown that the material is lightweight $\left(404.4-483.5 \mathrm{~kg} / \mathrm{m}^{3}\right)$ and a high total porosity $(78.7-80.8 \%)$ determines low thermal conductivity $(\lambda=0.088-0.122 \mathrm{~W} /(\mathrm{m} \cdot \mathrm{K}))$. Wall thickness of about $400 \mathrm{~mm}$ (including timber elements of frame) can meet the statutory thermal requirements for external walls without additional thermal insulation for Polish Standards (in the case of HLC 4 with $\lambda=0.088 \mathrm{~W} /(\mathrm{m} \cdot \mathrm{K})$ ).

Regardless of the recipe, the composites are characterized by high mass absorptivity (111.2 to $138.2 \%$ ). It decreases with the increase of the binder content, however, it also results in a decrease in thermal insulation.

The tested composites have low strength characteristics. The compressive strength of composites ranges from 0.23 to $0.32 \mathrm{MPa}$, and the flexural strength ranges from 0.086 to $0.111 \mathrm{MPa}$. Composite is not a load bearing material, but is used as a filling in walls with load bearing timber frame construction. The presence of fibrous and cellulosic material determines the specific form of deformation during the load test and the lack of sudden destruction.

Future research could be focused on the use of additives which could increase the mechanical durability of the hemp lime composites in order to eliminate a load-bearing timber frame construction and which could increase the waterproofness of composites.

The condition for the development of popularity of the use of this composite is the increase in the area of industrial hemp cultivation. In countries where crops are small, it is necessary to import shives, which may increase the overall costs of composite production. The problem in some countries is also the lack of suitable harvesting machines and efficient technological lines for the production of shives, which could reduce the production costs of the composite. However, interest in industrial hemp crops is increasing, which may be a good prediction of the wider use of shives in construction industry.

\section{References}

1. A. Chel, and G. Kaushik, Renewable energy technologies for sustainable development of energy efficient building, (Alexandria Eng. J., Available online 19 April 2017)

2. P. Kosiński, P. Brzyski, A. Szewczyk, and W. Motacki, Thermal Properties of Raw Hemp Fiber as a Loose-Fill Insulation Material, (J Nat Fibers, Available online 2017)

3. P. Brzyski, D. Barnat-Hunek, Z.Suchorab and G. Łagód, Materials, 10(5) (2017)

4. N. Stevulova, L. Kidalova, J. Junak, J. Cigasova, E. Trepakova, Procedia Eng, 42, 496-500 (2012)

5. M. Rahim, O. Douzane, A.D. Tran Le, G. Promis, and T. Langlet, Constr. Build. Mat., 102(1), 679-687 (2016)

6. R. Walker, and S. Pavia, Constr.Build.Mat., 64, 270-276 (2014)

7. E. Sassoni, S. Manzi, A. Motori, M. Montecchi, and M. Canti, Energ Buildings, 77, 219-226 (2014)

8. S. Pretot, F. Collet, and C. Garnier, Build Environ, 72, 223-231 (2014)

9. L. Arnaud, and E. Gourlay, Constr. Build. Mat., 28(1), 50-56 (2012)

10. P. Brzyski, and M. Widomski, AIP Conference Proceedings, 1866(040006-1) (2017)

11. S. Benfratello, C. Capitano, G. Peri, G. Rizzo, G. Scaccianoce, and G. Sorrentino, Constr. Build. Mat., 48, 745-754 (2013)

12. G. Balčiūnas, S. Vèjelis, L. Lekūnaitè, and A. Kremensas, Environ Eng Manag J, 15(3), 699-705 (2016)

13. A. Shea, M. Lawrence, and P. Walker, Constr. Build. Mat., 36, 270-275 (2012) 